\title{
From BIM towards Digital Twin: Strategy and Future Development for Smart Asset Management
}

\author{
Qiuchen $\mathrm{Lu}^{1}$, Xiang Xie ${ }^{1}$, James Heaton ${ }^{1}$, Ajith Kumar Parlikad ${ }^{1}$, and Jennifer \\ Schooling ${ }^{2}$ \\ 1. Institute for Manufacturing (IfM), University of Cambridge, Cambridge, CB3 OFS, UK \\ 2. Cambridge Centre for Smart Infrastructure and Construction (CSIC), University of Cam- \\ bridge, Cambridge, CB2 1PZ, UK \\ $\{q 1284$, xx809, jrh212, aknp2, jms33\}@cam.ac.uk
}

\begin{abstract}
With the rising adoption of Building Information Model (BIM) for asset management within architecture, engineering, construction and owner-operated (AECO) sector, BIM-enabled asset management has been increasingly attracting more attentions in both research and practice. This study provides a comprehensive review and analysis of the state-of-the-art latest research and industry standards development that impact upon BIM and asset management within the operations and maintenance (O\&M) phase. However, BIM is not always enough in whole-life cycle asset management, especially in the O\&M phase. Therefore, a framework for future development of smart asset management are proposed, integrating the concept of Digital Twin (DT). DT integrates artificial intelligence, machine learning and data analytics to create dynamic digital models that are able to learn and update the status of the physical counterpart from multiple sources. The findings will contribute to inspiring novel research ideas and promote widespread adoption of smart DT-enabled asset management within the O\&M phase.
\end{abstract}

Keywords: Building information model (BIM), Digital Twins (DT), asset management, operations and maintenance (O\&M)

\section{Introduction and Current Research}

Considering BIM for asset management, a bunch of publications were reviewed from journals, conference proceedings and other sources of professional associations. Numerous recent developments not only focus on implementation and research in BIMenabled asset management areas from technical aspects [1,2] but also put great efforts in improving the performance of asset management in O\&M phases from the perspective of management and organisation [3,4]. These improvements can be classified as technology related issues, information related issues and organisation related issues $[5,6]$. The effectiveness of asset management in the O\&M phase will heavily rely on continuous information on asset conditions and performances, reliable communication channels and properly documented professional knowledge from previous experience [6-8]. Obviously, BIM would aid in overcoming some of the complex problems in the

adfa, p. 1, 2011.

(C) Springer-Verlag Berlin Heidelberg 2011 
O\&M phase [9,10]. Building/infrastructure related information can be directly or indirectly integrated within available digital technologies in a BIM-enabled environment. As shown in Table 1, many researchers have focused on developing high-performance BIM-enabled asset management systems. Targets and benefits of current BIM-enabled asset management can be summarized as follows:

- Accurate and efficient support for decision-making, monitoring and communication;

- Easy retrieval and storage of maintenance, inventory, warranty, installation and operation data;

- Enhance collaboration and increase visualisation;

- Effective management and planning of orders, activities, schedules, labour and space;

- Convenient maintenance and tracking of assets;

- Optimised use of fuel, utilities and materials;

- Facilitate emergency evacuation planning.

Besides depicting state-of-the-art implementation, the following sections not only discuss the benefits and limitations of current research and standards in asset management but also include potential developments towards Digital Twin (DT)-enabled asset management.

Table 1. Brief summary of BIM-enabled asset management development

\begin{tabular}{|c|c|c|c|}
\hline Author/year & Technologies & Key algorithms/tools & Brief introduction \\
\hline $\begin{array}{l}\text { Shen et al. } \\
(2012)[11]\end{array}$ & $\begin{array}{l}\text { Wireless sen- } \\
\text { sor /RFID- } \\
\text { based real- } \\
\text { time asset } \\
\text { tracking, BIM }\end{array}$ & Agent-based web services & $\begin{array}{l}\text { Presenting a conceptual framework } \\
\text { of the proposed agent-based service- } \\
\text { oriented integration approach for fa- } \\
\text { cility lifecycle information integra- } \\
\text { tion }\end{array}$ \\
\hline $\begin{array}{l}\text { Dibley et al. } \\
(2012)[12]\end{array}$ & Sensor, IFC & $\begin{array}{l}\text { Ontology development in- } \\
\text { cluding sensor and building } \\
\text { ontology }\end{array}$ & $\begin{array}{l}\text { Presenting an intelligent multi-agent } \\
\text { software framework (OntoFM) sup- } \\
\text { porting real time building monitor- } \\
\text { ing }\end{array}$ \\
\hline $\begin{array}{l}\text { Lee et al. } \\
\text { (2013) [13] }\end{array}$ & $\begin{array}{l}\text { Sensor, BIM, } \\
\text { GIS, Ubiqui- } \\
\text { tous Sensor } \\
\text { Network, Ur- } \\
\text { ban Object } \\
\text { Identification }\end{array}$ & $\begin{array}{l}\text { Integration of facilities-re- } \\
\text { lated information and integra- } \\
\text { tion of management functions }\end{array}$ & $\begin{array}{l}\text { Presenting intelligent urban facilities } \\
\text { management for real-time emer- } \\
\text { gency response }\end{array}$ \\
\hline $\begin{array}{l}\text { Ko et al. } \\
(2013)[14]\end{array}$ & $\begin{array}{l}\text { RFID, Web- } \\
\text { based system, } \\
\text { Database }\end{array}$ & $\begin{array}{l}\text { Four-layer fuzzy neural net- } \\
\text { work model, scheduling the- } \\
\text { ory }\end{array}$ & $\begin{array}{l}\text { Developing a web-based RFID FM } \\
\text { system for enhancing facility man- } \\
\text { agement efficiency }\end{array}$ \\
\hline $\begin{array}{l}\text { Lin et al. } \\
(2013)[15] \\
(2014)[16]\end{array}$ & $\begin{array}{l}\text { Mobile, Bar- } \\
\text { code, Data- } \\
\text { base, BIM }\end{array}$ & $\begin{array}{l}\text { An information centre for } \\
\text { data querying }\end{array}$ & $\begin{array}{l}\text { Proposing a mobile automated BIM- } \\
\text { based facility management } \\
\text { (BIMFM) system for FM staff in the } \\
\text { O\&M phase }\end{array}$ \\
\hline $\begin{array}{l}\text { Motamedi et } \\
\text { al. (2015) [17] }\end{array}$ & $\begin{array}{l}\text { CMMS, } \\
\text { COBIE, IFC, } \\
\text { BIM }\end{array}$ & $\begin{array}{l}\text { Data integration via connect- } \\
\text { ing unique ID; } \\
\text { Knowledge capture using } \\
\text { fault trees. }\end{array}$ & $\begin{array}{l}\text { Providing a knowledge-assisted } \\
\text { BIM-based visual analytics ap- } \\
\text { proach for failure root-cause detec- } \\
\text { tion in FM }\end{array}$ \\
\hline $\begin{array}{l}\text { Kang and } \\
\text { Hong }(2015) \\
{[18]}\end{array}$ & $\begin{array}{l}\text { GIS, BIM, } \\
\text { IFC, } \\
\text { CityGML }\end{array}$ & $\begin{array}{l}\text { BIM/GIS-based information } \\
\text { Extract, Transform, and Load } \\
\text { (BG-ETL) architecture }\end{array}$ & $\begin{array}{l}\text { Proposing a software architecture for } \\
\text { the effective integration of BIM into } \\
\text { a GIS-based FM system }\end{array}$ \\
\hline
\end{tabular}




\begin{tabular}{llll}
\hline $\begin{array}{l}\text { Róka-Mada- } \\
\text { rász et al. } \\
\text { (2016) [19] }\end{array}$ & $\begin{array}{l}\text { CAFM, CAD, } \\
\text { Database }\end{array}$ & $\begin{array}{l}\text { Top-down object hierarchy; } \\
\text { Geometric Description Lan- } \\
\text { guage }\end{array}$ & $\begin{array}{l}\text { Elaborating a methodology to gath- } \\
\text { ering building O\&M costs data }\end{array}$ \\
\hline $\begin{array}{l}\text { Shalabi et al. } \\
\text { (2016) [20] }\end{array}$ & $\begin{array}{l}\text { BIM, IFC, } \\
\text { BEMS, BAS }\end{array}$ & $\begin{array}{l}\text { linking alarm reports of } \\
\text { equipment failures with IFC } \\
\text { BIM }\end{array}$ & $\begin{array}{l}\text { Proposing an automated process that } \\
\text { responds to alarms by retrieving } \\
\text { alarms reported by FM systems for } \\
\text { corrective maintenance }\end{array}$ \\
\hline $\begin{array}{l}\text { Peng et al. } \\
\text { (2017) [21] }\end{array}$ & $\begin{array}{l}\text { Data ware- } \\
\text { house, BIM }\end{array}$ & $\begin{array}{l}\text { Clustering algorithm; Cluster- } \\
\text { based frequent pattern mining } \\
\text { algorithm }\end{array}$ & $\begin{array}{l}\text { Proposing a BIM-based Data Mining } \\
\text { approach for extracting meaningful } \\
\text { patterns and detecting improper rec- } \\
\text { ords }\end{array}$ \\
\hline $\begin{array}{l}\text { Arslan et al. } \\
\text { (2017) [22] }\end{array}$ & BIM, Sensor & Hadoop; Distributed storage & $\begin{array}{l}\text { Develop a proactive safety facility } \\
\text { management system }\end{array}$ \\
\hline $\begin{array}{l}\text { Suprabhas et } \\
\text { al. (2017) [23] }\end{array}$ & $\begin{array}{l}\text { BIM, Sensor, } \\
\text { COBIE }\end{array}$ & $\begin{array}{l}\text { Data integration and visuali- } \\
\text { sation }\end{array}$ & $\begin{array}{l}\text { Developing an application that inte- } \\
\text { grates sensor data and reports the } \\
\text { data via the virtual model of the } \\
\text { building. }\end{array}$ \\
\hline $\begin{array}{l}\text { Hu et al. } \\
(2018) \text { [24] }\end{array}$ & $\begin{array}{l}\text { BIM, GIS, } \\
\text { BAS, Web- } \\
\text { service, QR } \\
\text { code/RFID }\end{array}$ & $\begin{array}{l}\text { Logic chain generation algo- } \\
\text { rithm; Equipment identifica- } \\
\text { tion and grouping algorithm }\end{array}$ & $\begin{array}{l}\text { Developing a cross-platform Me- } \\
\text { chanical, Electrical and Plumbing } \\
\text { (MEP) management system }\end{array}$ \\
$\begin{array}{l}\text { BIM, IFC, Fa- } \\
\text { (2018) [25] }\end{array}$ & $\begin{array}{l}\text { A* algorithm used for opti- } \\
\text { mal maintenance path plan- } \\
\text { ment systems } \\
\text { for maintenance scheduling }\end{array}$ & $\begin{array}{l}\text { Proposing a BIM-based framework } \\
\text { for automatic scheduling of facility } \\
\text { maintenance work orders }\end{array}$ \\
\hline
\end{tabular}

Note: GIS: geographic information system; RFID: radio frequency identification devices; BEMS: building energy management systems; Hadoop: Highly Archived Distributed Object-Oriented Programming.

A DT refers to an integrated multifaceted and multiscale digital replica of physical assets, processes and systems [26]. There are several definitions of DTs. In the context of Digital Built Britain, a digital twin is "a realistic digital representation of assets, processes or systems in the built or natural environment" [27]. GE defines a DT as "a dynamic digital representation of an industrial asset, that enables companies to better understand and predict the performance of their machines and find new revenue streams, and change the way their business operates" [28]. HVM Catapult states that a DT is a model of the physical object or system, which connects between digital and physical assets, transmits data in at least one direction and monitors the physical system in real time. In addition, DTs also should support analytics, control and simulation functions [29]. In order to provide clear descriptions of DTs in AEC/FM fields based on Gemini principles [27], DTs can be constructed in different scales (e.g., individual asset scale, network/system scale, city scale), built for various purposes, and using different approaches, but they are all built on data.

\section{Industry Standards and their Scopes}

\subsection{Overall Introduction of Industry Standards}

This section aims to review the current industry standards, specification and guidance as produce by standardisation organisations and regulatory bodies, in the domains of BIM and asset management firstly. The challenge to implement BIM within asset 
management is multifaceted and with one of the key challenges being the information capture, exchange, use and management throughout an assets whole-life (design, construction, O\&M and disposal/renew). As such, it is also a requirement to review data interoperability related standards within the scope of BIM and asset management. Most notability the exchange of information from design and construction phase into the O\&M phase.

There is an array of standards that focus on BIM and information management processes within an assets life-cycle, the most comprehensive standards have been developed by BSI and ISO. Fig. 1 highlights the key standards and specifications as per there associated lifecycle. The bulk of the standards focus on the design and construction phase. A few standards that are associated with the O\&M phase focus on the exchange of information and geometry from design and construction into O\&M phase not specifically focused on using BIM for asset management. Furthermore, there is a strong focus to support the end-user, operator and maintainer engagement at the easily stages within the design phase to capture their requirements.

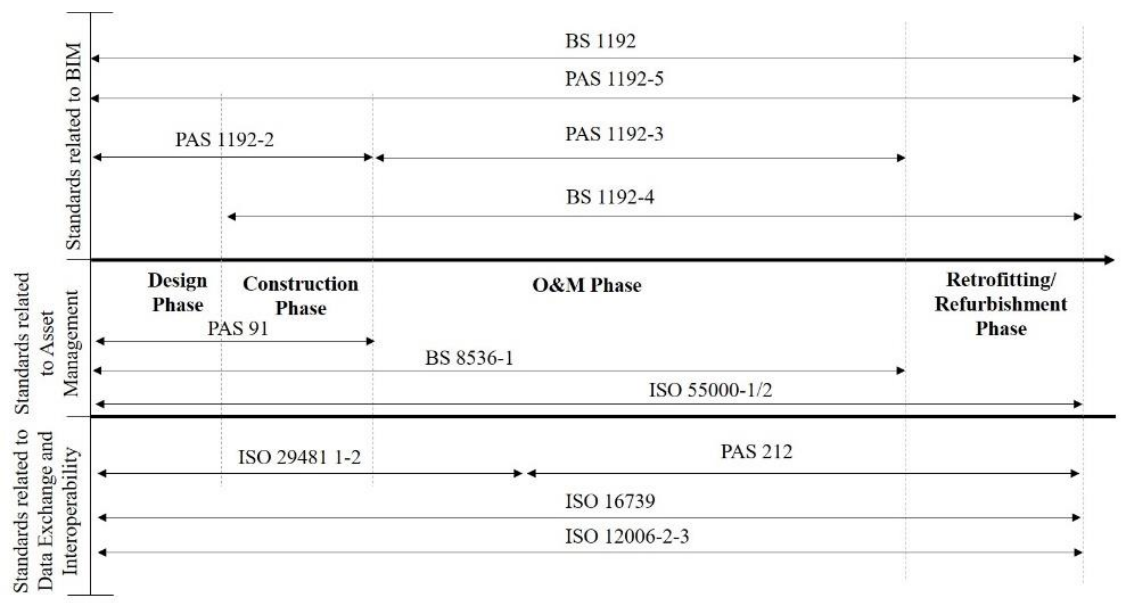

Fig. 1. Summary of standards throughout an asset whole-life

\subsection{Asset Management related Standards}

Asset management is a set of management processes and systems that encompass the management of an asset throughout its whole life cycle. This includes management of the physical asset and the related digital information within the context of the organisation. One of the key objectives on implementing an asset management system is the ability to diffuse the traditional organisational siloed effect, as an example, the capital works department not consulting the maintenance department, for their requirements within new construction work.

ISO 55000:2014 (formally PAS 55/1/2) is a series of standards (three in total) that focus on the development of an asset management system for an asset-centric organisation. The standards are strategic in nature and support the management processes. 
This includes overview, principles, terminology, requirements and guidance for the application of the requirements. A fundamental goal of asset management involves the balancing of cost, opportunities and risk against the desired performance of assets, to achieve the organisation objectives. The performance of the assets can be measured in different value requirements including not just the traditional measurement of financial value but also environmental and social value.

Furthermore, an industry representative body for asset managers in the UK, the Institute of Asset Management (IAM), has developed a collection of guidance documentation in collaboration with industry to support the development of an asset management system. This guidance includes the development of asset management related documentation, developing performance measures, how to make improvements of the concepts and philosophy of asset management.

While the standards provide the foundation for the development of an asset management system they are limited in providing technical guidance. Firstly, they fail to incorporate the emerging BIM processes, limiting the use of BIM within the O\&M phase of an asset. Secondly, not an efficient amount of focus is given to the information management processes requirements within asset management. Finally, no framework is given that aids in aligning the organisational requirements with the asset information requirements, and limiting the value of information that is collected from the organisation's assets.

\subsection{BIM related Standards}

BIM is an emerging process of designing, constructing or operating a building or infrastructure asset using digital object-oriented information. The development and implementation throughout the different lifecycle of an asset are supported by an array of standards that have been developed by multiple country standards and regulations organisations. Most notability the BSI has developed a comprehensive array of BIM related standards focusing on individual lifecycle phases, including design, construction and operational. The BSI BIM related standards lay down the foundation for how information should be defined, collected, exchanged, stored, used and disposed off within the context of BIM information management processes. While BIM has been widely adopted within the design and construction phase, its adoption within the operation and maintenance phase is limited. This is partly due to the multifaced complex challenges of asset management and the alignment of the asset management frame to the BIM information management processes.

Actually, the scope of BIM is board and encompasses the information management processes of an assets whole-life with many stakeholders. While the standards provide the theory and concept of BIM, several limitations are summarised in this study. Firstly, the concept is well described, but there is no methodology provided for implementation. Secondly, due to the broadness of BIM, the standards and specifications often lack technical detail. Finally, PAS 1192-3 BIM for the O\&M phase fails to address the multifaceted challenges within adopting BIM for the O\&M phase. The summarised BIM standards have been created in isolation of any organisational management processes and as such fail to address the core processes of asset management. Furthermore, they 
lack support to allow a holistic organisational adoption of BIM, especially in O\&M phases. This is partly due to the fact that the standard fails to clearly address stakeholder requirements within BIM domain, simplify the exchange from design/construction into the O\&M phase and lack of understanding how information is used within the O\&M phase.

\subsection{Data Exchange and Interoperability related Standards}

In order to support the implementation of BIM and asset management, there is a fundamental need to standardise the exchange of geometric and nongeometric information among different stakeholders in O\&M phases, and this requirement has resulted in a concept called openBIM. openBIM is a set of open source data standards for the exchange of information between BIM authoring and validation tools. Most notably, BuildingSMART has aided in developing the opensource data format IFC that supports the exchange of BIM related information and has been widely adopted by software developers. One of the key advantages of IFC is the interoperability that it enables, supporting the exchange of BIM models between different enterprise software providers. For example, a designer can exchange the IFC model with the quantity surveyor about cost estimation issues without using incompatible native formats. IFC's overall goal is to support the exchange of information within an open source standard throughout an assets whole-life, and this broad goal makes it an extensible information model.

\subsection{Summary}

While, there is a growing set of standards that aim to enable the development of BIM within O\&M and asset management, there is a fundamental lack of a framework to support this development. Most notably there are no holistic overarching frameworks that support the alignment of strategic, process and technical standards. This is witnessed within the standard for classification of built environment assets (ISO 12006-2), as this standard does not align to the information management processes for the built environment assets (PAS 1192-3 / ISO 55000-1/2). Furthermore, the standards have often been developed for individual lifecycles and disciplines, resulting in limited usage throughout the whole-life cycles, as can be whiteness within the limited IFC classes and property sets that have limited support for infrastructure projects and O\&M requirements. Finally, there is a lack of the understanding of the organisation context of asset owners. While ISO 55000 supports the development of management processes within asset management, it doesn't align to information management processes such as PAS 1192-3 or ISO 12006-2, therefore creates a disconnect from the organisational context and information management processes for their built environment assets.

\section{$3 \quad$ Limitations of Current Research and Standards}

In order to provide a comprehensive view, BIM-enabled asset management in this study is described within its technical, informational, and organizational issues. Many 
organizations and researchers have made significant efforts to accelerate the development of BIM-enabled asset management in the O\&M phase from technology, information, organisation and standard perspectives. There are still many issues that need to be addressed to meet the requirements of O\&M. Based the aforementioned analysis, corresponding limitations and gaps are still needed to put forward from these four perspectives. The following table 2 provides a comprehensive summary of limitations and gaps in current research and standards for achieving smart asset management in O\&M phases.

Table 2. Limitations and gaps of current research and standards for developing smart asset management in O\&M phases

\begin{tabular}{|c|c|}
\hline Technology related issues & $\begin{array}{l}\text { Lacking a well-organised demonstrator and guideline for technology se- } \\
\text { lection, design and integration; } \\
\text { Lacking integrating BIM with various CAFM systems; } \\
\text { Lacking integrating BIM with other systems; e.g., Locating and navi- } \\
\text { gating in a complex BIM environment is difficult, when barcoding/tags } \\
\text { are not properly linked with BIM; } \\
\text { Lacking integration among various applied systems; } \\
\text { Lacking clear and logical plans for updating as-is BIM; }\end{array}$ \\
\hline Information related issues & $\begin{array}{l}\text { Lacking a predefined strategy of transforming different information; } \\
\text { e.g., natural languages, expert experience, digital data etc.; } \\
\text { Lacking a customised and extensible database for different types of in- } \\
\text { formation; } \\
\text { Information aspects in the CAFM systems not matching those in the } \\
\text { BIM authoring tools; } \\
\text { Lacking clear defined strategies for information saving, exchanging and } \\
\text { sharing; } \\
\text { Lacking specifying LODs requirements for BIM in O\&M phases; } \\
\text { Lacking specific information requirements according to the organiza- } \\
\text { tional roles; } \\
\text { Lacking knowledge for specifying requirements of asset management } \\
\text { early in the design phases; }\end{array}$ \\
\hline Organisation related issues & $\begin{array}{l}\text { Lacking understanding of learning processes for BIM in maintenance in } \\
\text { the early building project stage; } \\
\text { Lacking an updated management mode (including people and facilities) } \\
\text { for smart BIM-enabled asset management in O\&M phases; } \\
\text { Lacking updated working and services workflows for smart BIM- } \\
\text { enabled asset management in O\&M phases; } \\
\text { Querying and updating routines are usually manual and time-consuming; } \\
\text { The BIM and systems are not fully integrated with the asset management } \\
\text { workflows; }\end{array}$ \\
\hline Standard related issues & $\begin{array}{l}\text { Lacking a recognised standard/ specification determining the specific } \\
\text { data requirements, BIM implementations, management processes and } \\
\text { strategies in a comprehensive view; } \\
\text { Standards have often been developed for use within individual lifecycle } \\
\text { stages and disciplines, resulting in inconcinnity throughout the assets } \\
\text { whole-life; } \\
\text { The developed standards are often generic in nature and fail to address } \\
\text { the particular implementation challenges; } \\
\text { There is little to no alignment between the different standards, resulting } \\
\text { in the strategic documentation that does not align to process or technical } \\
\text { requirements. }\end{array}$ \\
\hline
\end{tabular}

Note: LODs: Level of details. 


\section{DT-enhanced Smart Asset Management}

With the basis of comprehensive analysis and limitations from the former sections, this study proposed the hierarchical architecture of the smart DT-enhanced asset management framework. Although BIM has been successfully adopted in the design and construction phases, it still has limited adoption within asset management. The research related to BIM and asset management is still at its infancy, but rapidly growing. The most important reason is that in daily O\&M management, BIM is not enough for complex situations and comprehensive data management considering the limitations listed in the former chapters.

The development of Level 3 BIM Strategy, which is known as "Digital Built Britain" (DBB), will further accelerate benefits and development of BIM and other digital technologies in the asset management sector based on the momentum created by Level 2 BIM. Furthermore, data for public good states that: "The UK needs a digital framework for data on infrastructure to harness the benefits from sharing better quality information about its infrastructure; how it is used, maintained and planned".

Hence, the digital twin (DT) is widely promoted. DT is a digital model, which is a dynamic representation of an asset and mimics its real-world behaviours. DT is built on data. However, in DTs' research, a clear-defined and well-organised framework is still needed to supervise their current implementations, identify the gaps and provide roadmaps for future development. Moreover, without such a framework, they are susceptible to omit some possible improvement and key limitations.

\section{A Framework for DT-enabled Asset Management in O\&M Phases}

Through a comprehensive literature review, we propose a framework for DTenabled asset management in the O\&M phase. From a practical viewpoint, four aspects of requirements (i.e., intelligence, efficiency, integration and interoperability) are considered for successful implementation of DT-enabled asset management. Intelligence means shifting from traditional manual and labour-intensive asset management to more active and automated approaches (e.g., automatic monitoring process, data-driven approaches, knowledge-led methods). Efficiency here means the ability to manage assets in the O\&M phase using effective ways with fewer resources required (e.g., time, cost, FM professionals, computational cost). Integration addresses that all assets (including data, technology, models etc.) can be compatible, integrated and further collaborate. Interoperability describes how smart DT-enabled asset management can be coherently dealt with various activities and seamlessly cooperated with other systems/people.

Key layers of achieving the 'smart' DT-enabled asset management are summarised and presented in Fig. 2.

Smart asset layer: The term "smart asset" used in this study refers to conducting asset management activities with high performance, such as digital techniques, as-is BIM and information and communication technology (ICT), and further has capacities cooperated with other assets. These smart assets will increase productivity in terms of 
their operational efficiencies in daily services. Due to technological advances (e.g., image-based techniques), contactless data exchange (e.g., RFID), distributed sensor systems, wireless communication, and mobile access (e.g., WiFi environment) are all available in the O\&M phase. Smart assets would be of immense importance for realtime data collection, effective communication and close integration with other assets. Moreover, as-is BIM models will be the central platform linking with different databases and systems in this perspective framework. An as-is BIM is used to describe the up-to-date BIM in the O\&M phase.

Smart asset integration layer: With the support of smart assets, there is a need to have a layer providing integration and interoperative services. IoT (including RFID, QR code, sensor systems and network technologies) can support seamless sensing and actuating devices to share information via a predefined framework and wireless technologies. Its framework is realized through ubiquitous sensor systems, data analytics, information representation and cloud computing. In the smart asset integration layer, IoT (including RFID, QR code, sensor systems, cloud computing and network technologies) provides open access to various selected subsets of data from their corresponding digital services and also supports extensible innovative applications. This layer also can connect assets (including involved people) into interactive and intelligent entirety.

Smart DT-enabled asset management layer: Successful development of smart DTenabled asset management can be achieved from the following four aspects: 1). a clear and well-defined framework for smart DT-enabled asset management, namely the perspective framework as shown in Fig.2; 2). an intelligent and seamless plan of integrating all assets during management processes, namely smart assets and smart asset integration layer; 3). a practical interoperability method for exchanging and storing information between DT and various FM systems/people, namely the digital twin and AIsupported decision-making systems. Digital twin will be introduced into this framework. It refers to an integrated multifaceted and multiscale digital replica of physical building/infrastructure, processes and systems. In this framework, the digital twin integrates IoT, AI, machine learning and existing software analytics with required data to create a dynamic digital platform that updates as-is conditions following the physical building/infrastructure asset. As-is conditions express the current conditions of assets, including work orders, operational information records, FM professional in charge, upto-date maintenance information, status etc. Moreover, AI-based intelligent systems would keep learning from experts with rich asset management knowledge for effectively making decisions about daily events and emergency issues. Finally, 4). an effective and efficient communication, cooperation and management system for users and FM professionals. For instance, site workers are required to be properly trained to understand the technologies and use the tools developed.

In general, this perspective framework is developed in this study to depict the meaning of smart DT-enabled asset management. Furthermore, it also provides a consolidated framework for both researchers and practitioners involved in DT or asset management to have a more detailed understanding of how to achieve smart DT-enabled asset management in O\&M phases. 

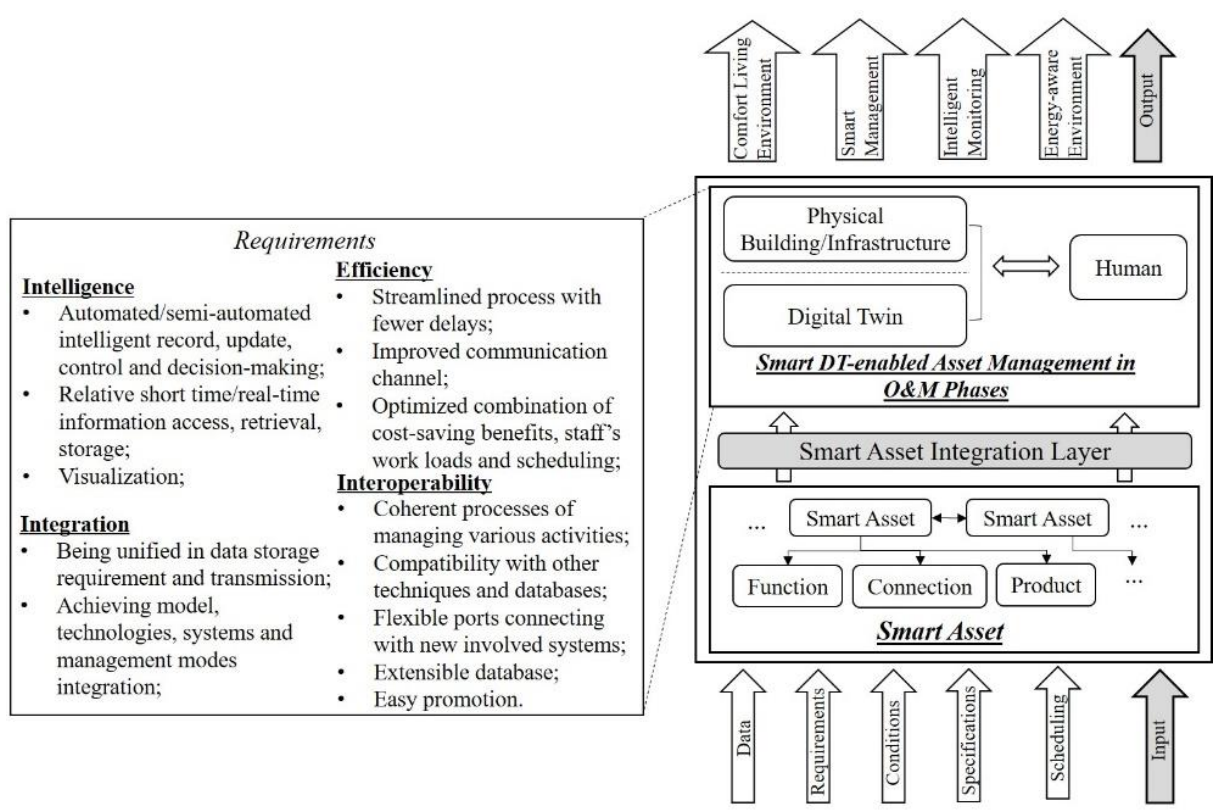

Fig. 2. The potential framework of the smart DT-enabled asset management in O\&M phases

\section{Conclusion}

With the extensive attention to implementations of smart asset management in the O\&M phase and the expectations to take all the advantages of BIM and digital techniques in asset management, this study provided a comprehensive review and analysis including both academic publications and industry standards. In order to present the insight into the new field of smart DT-enabled asset management in the O\&M phase, this study gives an overview of academic publications related to BIM-enabled asset management and associated industry standards by summarizing various works in different areas and provides possibilities to achieve the goal of transforming to DTenabled asset management. Detailed limitations and knowledge gaps have been discussed and a perspective frame-work is also presented. Furthermore, it is also clear that more efforts should be made based on the proposed perspective framework. This effective improvement is an important concern because all assets should be incorporated and integrated seamlessly. Moreover, the digital twin and AI-supported decision-making systems would highly improve the intelligence and integration of the whole system. From the standard aspects, the effective and efficient communication, cooperation and management mode would be a close linkage between people and processes.

Future works are however needed to 1). based on the perspective framework, further the detailed concepts and a case study in real practice of smart DT-enabled asset management will be developed; 2). the smart DT-enabled asset management at building/in- 
frastructure will be extended to city level development.; 3). research should be conducted to investigate the alignment of the pro-posed framework with the emerging domain of smart cities, specify aligning smart assets with smart cities; 4). the interaction and impact of a smart asset with the diverse stakeholders (including customers and the general public) need to be better understood.

\section{Acknowledgements}

This research that contributed to this paper was funded by the EPSRC/Innovate UK Centre for Smart Infrastructure and Construction (CSIC) and Centre for Digital Built Britain (CDBB) at the University of Cambridge.

\section{Reference}

1. N.D. Aziz, A.H. Nawawi, N.R.M. Ariff, ICT evolution in facilities management (FM): building information modelling (BIM) as the latest technology, Procedia-social and behavioral sciences 234 (2016) 363-371.

2. M. Gray, J. Gray, M. Teo, S. Chi, F. Cheung, Building Information Modeling, An International Survey, Brisbane, Australia, 2013.

3. A. Akbarnezhad, K.C.G. Ong, L.R. Chandra, Economic and environmental assessment of deconstruction strategies using building information modeling, Automation in construction 37 (2014) 131-144.

4. S. Chotipanich, Positioning facility management, Facilities 22 (13/14) (2004) 364-372.

5. R. Volk, J. Stengel, F. Schultmann, Building Information Modeling (BIM) for existing buildings-Literature review and future needs, Automation in Construction 38 (2014) 109127.

6. S.O. Alvarez-Romero, Use of Building Information Modeling Technology in the Integration of the Handover Process and Facilities Management, Worcester Polytechnic Institute, 2014, Dissertation, Last accessed March 10, 2018 from https://www.wpi.edu/Pubs/ETD/Available /etd-090914.../Disertation_final_SA.pdf.

7. E.A. Pärn, D.J. Edwards, M.C.P. Sing, The building information modelling trajectory in facilities management: A review, Automation in construction 75 (2017) 45-55.

8. Q. Lu, L. Chen, S. Lee, X. Zhao, Activity theory-based analysis of BIM implementation in building O\&M and first response, Automation in Construction 85 (2018) 317-332.

9. L. Sabol, Challenges in cost estimating with building information modeling, IFMA World Workplace, 2008, Last accessed November 01, 2017 from http://www.dcstrategies.net/files/2_sabol_cost_estimating.pdf.

10. M. Kassem, G. Kelly, N. Dawood, M. Serginson, S. Lockley, BIM in facilities management applications: a case study of a large university complex, Built environment project and asset management 5(3) (2015) 261-277.

11. W. Shen, Q. Hao, Y. Xue, A loosely coupled system integration approach for decision support in facility management and maintenance, Automation in construction 25 (2012) 41-48.

12. M. Dibley, H. Li, Y. Rezgui, J. Miles, An ontology framework for intelligent sensor-based building monitoring, Automation in Construction 28 (2012) 1-14. 
13. J. Lee, Y. Jeong, Y.S. Oh, J.C. Lee, N. Ahn, J. Lee, S.H. Yoon, An integrated approach to intelligent urban facilities management for real-time emergency response, Automation in construction 30 (2013) 256-264.

14. C.H. Ko, N.F. Pan, C.C. Chiou, Web-based radio frequency identification facility management systems, Structure and infrastructure engineering 9(5) (2013) 465-480.

15. Y.C. Lin, Y.C. Su, Developing mobile-and BIM-based integrated visual facility maintenance management system, The scientific world journal (2013).

16. Y.C. Lin, Y.C. Su, Y.P. Chen, Developing mobile BIM/2D barcode-based automated facility management system, The Scientific World Journal (2014).

17. A. Motamedi, A. Hammad, Y. Asen, Knowledge-assisted BIM-based visual analytics for failure root cause detection in facilities management, Automation in construction 43 (2014) 73-83.

18. T.W. Kang, C.H. Hong, A study on software architecture for effective BIM/GIS-based facility management data integration, Automation in construction 54 (2015) 25-38.

19. L. Róka-Madarász, L. Mályusz, P. Tuczai, Benchmarking facilities operation and maintenance management using cafm database: Data analysis and new results, Journal of building engineering 6 (2016) 184-195.

20. F. Shalabi, Y. Turkan, IFC BIM-based facility management approach to optimize data collection for corrective maintenance, Journal of performance of constructed facilities 31(1) (2016) 04016081.

21. Y. Peng, J.R. Lin, J.P. Zhang, Z.Z. Hu, A hybrid data mining approach on BIM-based building operation and maintenance, Building and environment 126 (2017) 483-495.

22. M. Arslan, Z. Riaz, S. Munawar, Building Information Modeling (BIM) Enabled Facilities Management Using Hadoop Architecture., Portland International Conference, Management of Engineering and Technology (PICMET), IEEE, Portland, 2017, pp.1-7.

23. K. Suprabhas, H.N. Dib, Integration of BIM and utility sensor data for facilities management, ASCE International Workshop on Computing in Civil Engineering 2017, Seattle, Washington, USA, 2017, pp. 26-33.

24. Z.Z. Hu, P.L. Tian, S.W. Li, J.P. Zhang, BIM-based integrated delivery technologies for intelligent MEP management in the operation and maintenance phase, Advances in engineering software 115 (2018) 1-16.

25. W. Chen, K. Chen, J.C. Cheng, Q. Wang, V.J. Gan, BIM-based framework for automatic scheduling of facility maintenance work orders, Automation in construction 91 (2018) 1530 .

26. G.L. Knapp, T. Mukherjee, J.S. Zuback, H.L. Wei, T.A. Palmer, A. De, T. DebRoy, Building blocks for a digital twin of additive manufacturing, Acta Materialia 135 (2017) 390-399, https://doi.org/10.1016/j.actamat.2017.06.039.

27. Centre for Digital Built Britain (CDBB), The Gemini Principles, 2018, from https://www.cdbb.cam.ac.uk/Resources/ResoucePublications/TheGeminiPrinciples.pdf.

28. GE Digital, Digital Twins: The Bridge Between Industrial Assets and the Digital World, 2017, from https://www.ge.com/digital/blog/digital-twins-bridge-between-industrial-assets-and-digital-world.

29. High Value Manufacturing Catapult Visualisation and VR Forum (HVM Catapult), Feasibility of an immersive digital twin: The definition of a digital twin and discussions around the benefit of immersion, 2018, from https://www.amrc.co.uk/files/document/219/1536919984_HVM_CATAPULT_DIGITAL_TWIN_DL.pdf. 